\title{
Factors associated with longevity: design and preliminary data of the MADRID+90 study
}

\author{
Miguel A. Fernández-Blázquez ${ }^{1}$, Teodoro del Ser ${ }^{1}$, Belén Frades-Payo ${ }^{1}$, Marina Ávila- \\ Villanueva $^{1}$, Meritxell Valentí-Soler ${ }^{1}$, María T. Benítez-Robredo ${ }^{2}$, Antonio Bermejo- \\ Acuña $^{3}$, Eduardo J. Pedrero-Pérez ${ }^{2}$, Javier Quilis Sancho ${ }^{1}$, Ana B. Pastor ${ }^{1}$, Concepción \\ Fernández-Garrido 2 , Sara Morales-Alonso ${ }^{2}$, José M. Diaz-Olalla ${ }^{2}$, Nadine Correia Santos ${ }^{4}$, \\ Fernando Maestú ${ }^{5,6}$, Jaime Gómez-Ramírez ${ }^{1}$ \\ ${ }^{I}$ Alzheimer Disease Research Unit, CIEN Foundation, Carlos III Institute of Health, \\ Queen Sofia Foundation Alzheimer Center. Madrid. Spain. \\ ${ }^{2}$ Evaluation and Quality Department, Madrid Salud, Madrid City Council. Madrid. Spain. \\ ${ }^{3}$ Municipal Statistics Service, S.D.G. for Statistics, Madrid City Council. Madrid. Spain. \\ ${ }^{4}$ Life and Health Sciences Research Institute (ICVS), School of Medicine, University of \\ Minho. Braga. Portugal. \\ ${ }^{5}$ Laboratory of Cognitive and Computational Neuroscience (UCM-UPM), Center for \\ Biomedical Technology, Campus de Montegancedo. Pozuelo de Alarcón, Madrid. Spain. \\ ${ }^{6}$ Department of Experimental Psychology, Complutense University of Madrid (UCM), \\ Campus de Somosaguas. Pozuelo de Alarcón, Madrid. Spain.
}

E-mail: mafernandez@fundacioncien.es

\begin{abstract}
The progressive ageing of the population represents a challenge for society. In particular, a strong increase in the number of people over 90 is expected in the next two decades. As this phenomenon will lead to an increase in illness and age-related dependency, the study of long-lived people represents an opportunity to explore which lifestyle factors are associated with healthy ageing and which with the emergence of age-related diseases, especially Alzheimer's type dementia. The project "Factors associated with healthy and pathologically aging in a sample of elderly people over 90 in the city of Madrid" (MADRID+90) brings together a powerful multidisciplinary research team in neurodegenerative diseases that includes experts in epidemiology, neurology, neuropsychology, neuroimaging and computational neuroscience. In the first phase of the project, a stratified random sampling was carried out according to the census of the city of Madrid followed by a survey conducted on 191 people aged 90 and over. This survey gathered information on demographics, clinical data, lifestyles and cognitive status. Here, the main results of that survey are showed. The second phase of the project aims to characterize individual trajectories in the course of either healthy and pathological ageing, from a group of 50 subjects over 90 who will undergo a comprehensive clinical examination comprised of neurological and cognitive testing, MRI and EEG. The ultimate goal of the project is to characterize the biophysical and clinical profiles of a population that tends to receive little attention in the literature. A better understanding of the rapidly increasing group of nonagenarians will also help to design new policies that minimize the impact and future social and economic consequences of the ageing phenomenon.
\end{abstract}




\section{INTRODUCTION}

The progress made during the 20th century in the social and environmental fields, as well as in medical care has led to an overall improvement in the state of health of the population and, consequently, to a reduction in mortality and a marked increase of life expectancy that is expected to continue in the coming decades. Indeed, the oldest-old subjects (i.e. individuals aged 90 years and older) will be more than 70 million worldwide in 2050, a 5-fold increase of the current number of this population (Nations, 2014; Rivoirard et al., 2014). But this increase, like the two sides of a coin, also may lead to an unprecedented increase in the number of people suffering from age-related diseases. In that scenario, dementia is called to occupy an important and unwelcoming place. The economic, social and personal costs related to dementia are devastating not only for the patients but also for their relatives. The prevalence of dementia after age 90 is expected to be around the $40 \%$ of the total oldestold population (Corrada et al., 2008).

However, still a considerable percentage of individuals remain cognitively normal at the oldest age. This fact underlies the importance of identifying protective factors for cognitive impairment in advanced age to set up and extend preventive strategies. For example, evidence suggests that longevity is associated with a heterogeneous set of factors such as genetic background (Revelas et al., 2018), physical exercise, especially when the Body Mass Index is between 20 and $25 \mathrm{~kg} / \mathrm{m} 2$ (Berrington de Gonzalez et al., 2010), efficacy in managing daily stress (Hadley et al., 2017), social support (Holt-Lunstad et al., 2010), having a purpose in life (Boyle et al., 2010), first-degree relatives of advanced age (Perls et al., 2002), ApoE $\varepsilon 2$ genotype (Pignolo, 2019), cardiovascular risk factors (Landi et al., 2018), diet quality (Naghshi et al., 2020) and others not well established yet. Thus, it should be noted that the main non-genetic risk factors for the development of dementia are related to potentially modifiable habits and lifestyles. Determining which of these factors or which combination of them play a protective role is crucial to design effective public health policies. Changes in society and improvements in living conditions and education in next decades can have a decisive influence not only on physical health, but also on mental and cognitive health and, therefore, on the incidence of dementia in the elderly population.

Probably, the best way to manage the economic and social consequences associated with the constant increase in life expectancy is to understand and control the factors that promote or reduce the longevity. However, the identification of the mechanisms related to the lengthening of life, as well as the complex interactions that occur between them, will require the construction of an inclusive framework of disciplines as disparate as genetics, medicine, psychology, sociology, epidemiology, demography or economics. Only a multidisciplinary approach can provide an adequate appraisal of such a complex phenomenon as healthy ageing and longevity.

On the other hand, predictive medicine aims to find out the potential diseases that an individual could develop to establish early preventive treatments. The integration of data mining and computing techniques may provide algorithms based on the processing of clinical, cognitive, genetic, demographic, and lifestyle data to identify a series of markers to estimate the risk of an individual to suffer a particular disease and to guide individualized preventive programs.

The project "Factors associated with healthy and pathologically aging in a sample of elderly people over 90 in the city of Madrid" (MADRID+90) has a genuine interdisciplinary approach and the purpose of fostering the exchange of ideas between researchers working in the fields of neurosciences, epidemiology, healthy aging and clinical pathology. In addition, the data obtained in this project will be compared with the available information generated within the framework of The Vallecas Project, a longitudinal investigation for the early detection of Alzheimer's disease (AD) in which an annual follow-up is carried out on all participants, including a neurological examination, a neuropsychological evaluation, a magnetic resonance imaging (MRI) study and a blood analysis (Olazarán et al., 2015; see https://www.biorxiv.org/content/10.1101/674853v2 to further details). This project was launched by Fundación CIEN in October 2011 with an initial cohort of 1,172 volunteers of both sexes, aged between 70 and 85 years; currently approximately 700 participants have completed the fifth visit to the study. It is important to note that the longitudinal nature of the Vallecas Project makes it a living project whose database grows daily as new evaluations are conducted. Therefore, the combination of the data obtained in both projects -MADRID+90 and Vallecas Project- will become a very valuable tool for the identification of healthy aging factors, as well as risk factors for the development of dementia related to lifestyle that are susceptible to be modified. Ultimately, the socio-demographic, clinical, cognitive and functional characterisation of a sample of people over 90 years of age of this research programme aims to disclose clues to delay the effects of cognitive ageing, reduce the risk of developing dementia, promote the level of functional independence and increase the quality of life of all older people. 


\section{Specific aims of MADRID+90}

The primary objectives of MADRID+90 are the following:

(1) To explore de phenotype of the cognitively normal oldest-old.

(2) To examine factors associated with successful aging and longevity in a cross-cultural study with people over the age of 90.

(3) To validate a set of clinical, cognitive and functional assessment instruments for the oldest-old.

(4) To determine the prevalence rates of dementia in people over 90 years according to their demographic and biological characteristics.

(5) To identify modifiable risk factors that may reduce the prevalence of dementia and increase the quality of life of older people.

The present paper describes the methodology of MADRID+90 and reports the results of this initial Wave 1 assessment to better understand living conditions of these segment of population.

\section{MATERIALS AND METHODS}

\section{Study design}

MADRID+90 is a multicentre, observational, two wave, cross-sectional study that will be conducted in two different waves as described below:

- Wave 1 - survey of persons aged 90 and over in the city of Madrid, Spain. The sample was randomly selected from the municipal census of Madrid which includes any person living in the city. This wave finished by the end of February 2020.

- Wave 2 - face-to-face evaluations which were expected to end by September 2020, but due to the COVID-19 pandemic are being slightly delayed. After wave 1, face-to-face evaluations are being currently carried out with those individuals who have given their written informed consent. A subsample of 50 individuals from Wave 1, with apparent normal cognition, will be selected to complete an extensive clinical exam (physical and -neurological examination, cognitive assessment, MRI, and EEG). The estimated time for completion of the whole exam is 3-4 hours with convenient breaks. A proxy and reliable informant will be also interviewed to complement and verify clinical and demographic information.

\section{Participants}

The sample was randomly selected from the municipal census of the city of Madrid, Spain, at the end of
September 2019. Two only inclusion criteria were considered: (i) the age of 90 years or older; and (ii) individuals should be independent and home-dwelling, therefore, non-institutionalized. The recruitment and examination of the participants for Wave 1 was carried out between October 2019 and February 2020. Registration in the municipal census is compulsory in Spain, and this is a database managed by the city councils. On 1st January 2019, 47,303 people over the age of 90 were registered in the city of Madrid, representing $1.5 \%$ of the city's total population. Based on a $95 \%$ confidence level and a $7 \%$ margin of error, a sample size of 200 was considered sufficient to achieve the proposed objectives.

A total of 824 non-institutionalised individuals were initially and randomly selected from the census and sent a letter inviting them to participate in the study. Then, two weeks later, an interviewer went to the homes of these candidates to ascertain their willingness to participate in the study. Of the 824 individuals invited to participate, 375 were not reached due to absence from home, change of residence or death. From the remaining 449 who were contacted to confirm eligibility. 258 declined after further information on the study. The final sample comprised 191 individuals who were interviewed at their homes with the presence, when possible, of a reliable informant. Figure 1 shows the flowchart of MADRID+90. The study was approved by the Ethics Committee of the Carlos III Institute of Health and all the participants signed informed consent before inclusion.

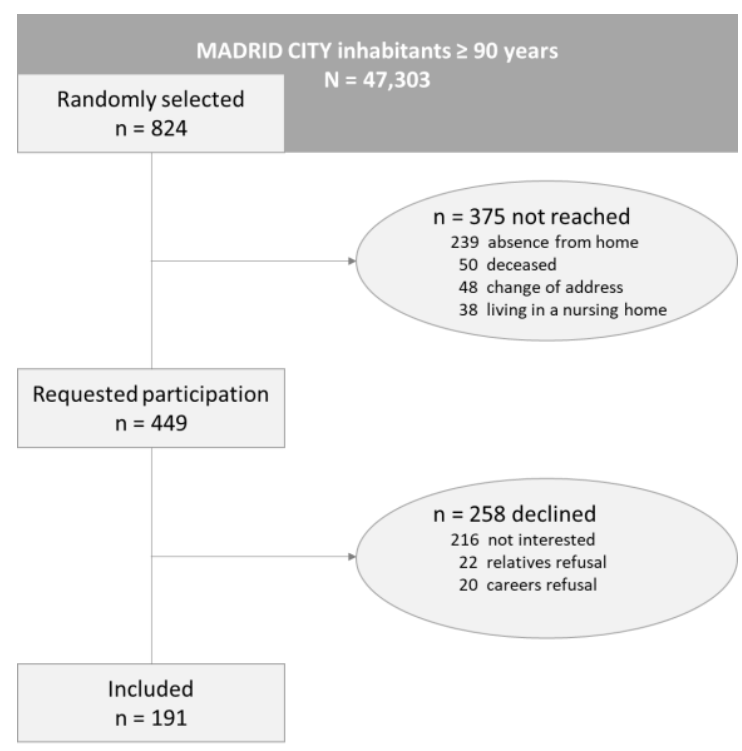

Figure 1. MADRID+90 flowchart.

\section{Assessments}

The Wave 1 surveys were conducted at the participants' homes by trained research staff. The complete visit took approximately 15 to 30 minutes. A structured questionnaire was used to collect information related to 
the following areas: demographic data, morbidity, medication, subjective cognitive decline, Spanish version of the Telephone Interview for Cognitive Status (TICS), perceived health, quality of life, functional dependence, and lifestyle habits. The responses of the participants, and the proxies when appropriate, were directly coded in electronic devices, so that the information was uploaded directly into the database. This procedure guarantees the traceability of the data and increases the quality of the information obtained.

On the other hand, the Wave 2 protocol is being applied in face-to-face visits to the facilities of Fundación CIEN to a subsample of 50 individuals recruited in Wave 1 and presumably without dementia. The protocol will include the following measures:

\section{Clinical and neurological exam}

A semi-structured clinical interview focused on neurological diseases, psychiatric disorders and family history of dementia is being conducted by a neurologist. A medical exam is also collecting systolic and diastolic blood pressure, heartbeat, reflexes, grip strength, signs of parkinsonism as well as the performance in brief motor tasks (Ashendorf et al., 2009; Podsiadlo \& Richardson, 1991). During the visit, the neurologist is estimating the visual, hearing and mobility function as "good", "moderate", "poor" or "very poor", according to a subjective classification previously used (Holstege et al., 2018). Additionally, for females age at menarche, onset of menopause, number of pregnancies and/or miscarriages are being also collected.

\section{Cognitive assessment}

A comprehensive neuropsychological battery is being administered by an experienced neuropsychologist to assess various cognitive domains important for the diagnosis of dementia and pre-dementia stages:

- Cognitive status: Mini Mental State Examination (MMSE) (Folstein et al., 1975); Clinical Dementia Rating (CDR) (Morris, 1993).

- Processing speed: Digit Symbol Coding (Wechsler, 1997).

- Verbal episodic memory: Free and Cued Selective Reminding Test (FCSRT) (Buschke, 1984).

- Attention / executive functions: Digit span Forward and Backward (Wechsler, 1997); Frontal Assessment Battery (FAB) (Dubois et al., 2000).

- Language: Lexical-Semantic fluency (letter P and animals in one minute) (Peña-Casanova et al., 2009); repetition of sentences (Peña-Casanova, 2005); Boston Naming Test 15-items version (FernándezBlázquez et al., 2012).

- Visuospatial: Incomplete Letter from the Visual Object and Space Perception (VOSP) Battery
(Warrington \& James, 1991).

- Visuoconstructive skills: Copy of Figures from the Revised Barcelona Test (Peña-Casanova, 2005); Clock Drawing Test (Cacho et al., 1999).

In addition, the cognitive assessment is completed with some specific scales on subjective cognitive decline (Miguel A. Fernández-Blázquez et al., 2018), depression (Yesavage et al., 1982), anxiety (Fernández-Blázquez et al., 2015; Spielberger et al., 1970), and functional state (Lawton \& Brody, 1969).

\section{MRI scans}

All participants in Wave 2 will be invited to undergo a MRI scan. Those who will agree will be screened for contraindications (pacemaker, metallic implant or foreign bodies, ferromagnetic clips, claustrophobia, etc.). All scans will be carried out in a 3-T MRI (Signa HDxt GEHC, Waukesha, WI, USA) equipped with a gradient system of $50 \mathrm{mT} / \mathrm{m}$. A phased array eight channels brain coil will be used for all the participants. The neuroimaging protocol will include the following sequences: (i) 3D T1-weigthed structural: 3D FSPGR with IR preparation (TR $10 \mathrm{~ms}$, TE $4.5 \mathrm{~ms}$, TI $600 \mathrm{~ms}$ ), field of view FOV $256 \mathrm{~mm}$, matrix $288 \times 288$, slice thickness $1 \mathrm{~mm}$ with no gap between; (ii) FLAIR: axial 2D FSE IR (repetition time TR $9000 \mathrm{~ms}$, echo time TE $130 \mathrm{~ms}$, TI $2100 \mathrm{~ms}$ ), FOV $256 \mathrm{~mm}$, slice thickness 3.4 $\mathrm{cm}$ with no gap between; (iii) T2-weighted: axial 2D GRE EPI (TR $3475 \mathrm{~ms}$, TE $27 \mathrm{~ms}$ ), FOV $256 \mathrm{~mm}$, matrix $262 \times 192$, slice thickness $3 \mathrm{~mm}$ with no gap between; (iv) diffusion weighted imaging (DWI): single shot spinecho echo-planar imaging sequence DWI SE-EPI (TR $9200 \mathrm{~ms}$, TE $80 \mathrm{~ms}$ ) with a-value of $800 \mathrm{~s} / \mathrm{mm} 2$ and 21 gradient directions FOV $256 \mathrm{~mm}$, matrix $128 \times 128$, slice thickness $3 \mathrm{~mm}$ with no gap between; (v) resting state (rs-fMRI): acquisition with blood oxygen level dependent (BOLD), without task, during 10 minutes (TR $2500 \mathrm{~ms}$, TE $27 \mathrm{~ms}$ ), FOV $250 \mathrm{~mm}$, matrix $96 \times 96$, slice thickness $3 \mathrm{~cm}$ with no gap between; and (vi) GABA spectroscopy: voxel of interest $\mathrm{VOI}=20 \times 20 \times 20 \mathrm{~mm} 3$ placed over prefrontal and precuneus areas using a STEAM sequence $(\mathrm{TE} / \mathrm{TM} / \mathrm{TR}=17 / 17 / 2000 \mathrm{~ms}$, sample size $=4096$, spectral bandwidth $=4000 \mathrm{~Hz}$, phase cycling $=8,288$ averages). The total time of each subject's scanning session will be approximately 50 minutes.

\section{EEG recording}

EEG will be recorded simultaneously from 32 channels corresponding to the International 10-20 System. Left and right earlobes (A1 and A2) will be marked as reference electrodes. EEG data will be recorded under resting state condition. Resting EEG recordings will be obtained under eyes open and eyes closed for 5 minutes each. The artefacts in the EEG signal will be removed us- 
Table 1. Sociodemographic characteristics of the sample.

\begin{tabular}{|c|c|c|c|c|}
\hline & $\begin{array}{l}\text { TOTAL } \\
(\mathrm{N}=191)\end{array}$ & $\begin{array}{c}\text { FEMALE } \\
(n=139)\end{array}$ & $\begin{array}{l}\text { MALE } \\
(n=52)\end{array}$ & p-value \\
\hline Age (median [IQR $\left.{ }^{\mathrm{a}}\right]$ ) & $92.64[91.61,94.89]$ & $93.01[91.74,95.32]$ & $91.88[91.45,94.44]$ & 0.027 \\
\hline \multicolumn{5}{|l|}{$\operatorname{Sex}(\%)$} \\
\hline Female & $139(72.8)$ & & & \\
\hline Male & $52(27.2)$ & & & \\
\hline \multicolumn{5}{|l|}{ Education (\%) } \\
\hline Illiterate & $32(16.8)$ & $28(20.1)$ & $4(7.7)$ & 0.021 \\
\hline Primary education & $100(52.4)$ & $74(53.2)$ & $26(50.0)$ & \\
\hline Secondary education & $49(25.7)$ & $33(23.7)$ & $16(30.8)$ & \\
\hline Higher education & $10(5.2)$ & $4(2.9)$ & $6(11.5)$ & \\
\hline \multicolumn{5}{|l|}{ Occupation (\%) } \\
\hline Management & $15(7.9)$ & $6(4.3)$ & $9(17.3)$ & $<0.001$ \\
\hline Professional & $18(9.4)$ & $10(7.2)$ & $8(15.4)$ & \\
\hline Office clerk & $19(9.9)$ & $14(10.1)$ & $5(9.6)$ & \\
\hline Skilled manual labor & $47(24.6)$ & $25(18.0)$ & $22(42.3)$ & \\
\hline Unskilled manual labor & $92(48.2)$ & $84(60.4)$ & $8(15.4)$ & \\
\hline \multicolumn{5}{|l|}{ Marital status (\%) } \\
\hline Single & $10(5.2)$ & $9(6.5)$ & $1(1.9)$ & $<0.001$ \\
\hline Married & $30(15.7)$ & $7(5.0)$ & $23(44.2)$ & \\
\hline Widowed & $151(79.1)$ & $123(88.5)$ & $28(53.8)$ & \\
\hline \multicolumn{5}{|l|}{ Life setting (\%) } \\
\hline Alone & $45(23.6)$ & $35(25.2)$ & $10(19.2)$ & 0.663 \\
\hline Spouse & $101(52.9)$ & $71(51.1)$ & $30(57.7)$ & \\
\hline Other accompanied & $45(23.6)$ & $33(23.7)$ & $12(23.1)$ & \\
\hline
\end{tabular}

ing simultaneous low-pass filtering and total variation denoising. The total time of each EEG session will be approximately 40 minutes.

\section{Planned statistical analyses}

Data from each sample shall be recorded together in a standardised and relational database. A strategy based on data mining techniques will be used for the purpose of comparing the information collected. Different models will be developed based both on classical parametric methods (linear models, logistic regression, etc.) and on supervised and unsupervised automatic learning algorithms (vector support machines, clusters, Bayesian classifiers, deep neural networks, etc.). The planned analysis strategy will be carried out in three different blocks depending on the information to be compared and the objectives to be met:

a) Analysis of the information obtained from the survey of Wave 1: this analysis aims to find out living conditions and to identify factors associated with successful ageing and longevity. First, the characteristics of the samples will be described, taking into account that they come from different socio-cultural backgrounds. Subsequently, based on the scores obtained by the participants of MADRID+90 on the TICS scale, the sociodemographic and lifestyle characteristics that differentiate the subjects with the best cognitive performance from those with the worst performance will be analysed. The analysis of all these factors will be carried out taking into account the temporal dynamics of their incidence on healthy ageing, as well as the mutual interactions between all of them.

b) Analysis of the information obtained from the face-to-face cognitive evaluations of Wave 2: this analysis will provide evidence to adapt and validate for the Spanish population a battery of clinical, cognitive and functional examination applicable to people over 90 years of age. This constitutes an important milestone in research on ageing insofar as it will provide specific assessment instruments for a segment of the population that is expected to increase substantially in the coming years.

c) Comparative analysis of the information obtained in the complete sample of MADRID+90 with that of the Vallecas Project: MADRID+90 will join synergies with the Vallecas Project for the early detection of AD (Olazarán et al., 2015) so that the conclusions obtained will be enriched. The comparison of the data from both waves of MADRID+90 together with the cohort of the Vallecas Project will deepen the knowledge of the factors associated with healthy aging, as well as better understanding of dementia risk markers. To this end, the MADRID+90 sample will act as a control group over which to compare two different subgroups of the Vallecas Project: i) individuals diagnosed as cognitively healthy in all their visits; and ii) individuals who have developed dementia 
Table 2. Clinical characteristics of the sample.

\begin{tabular}{|c|c|c|c|c|}
\hline & $\begin{array}{l}\text { TOTAL } \\
(\mathrm{N}=191)\end{array}$ & $\begin{array}{c}\text { FEMALE } \\
(n=139)\end{array}$ & $\begin{array}{l}\text { MALE } \\
(n=52)\end{array}$ & p-value \\
\hline \multicolumn{5}{|l|}{ Hypertension (\%) } \\
\hline No & $61(31.9)$ & $45(32.4)$ & $16(30.8)$ & \multirow[t]{2}{*}{0.864} \\
\hline Yes & $130(68.1)$ & $94(67.6)$ & $36(69.2)$ & \\
\hline \multicolumn{5}{|l|}{ Hypercholesterolemia (\%) } \\
\hline No & $165(86.4)$ & $123(88.5)$ & $42(80.8)$ & \multirow[t]{2}{*}{0.234} \\
\hline Yes & $26(13.6)$ & $16(11.5)$ & $10(19.2)$ & \\
\hline \multicolumn{5}{|l|}{ Diabetes (\%) } \\
\hline No & $154(80.6)$ & $115(82.7)$ & $39(75.0)$ & \multirow{2}{*}{0.303} \\
\hline Yes & $37(19.4)$ & $24(17.3)$ & $13(25.0)$ & \\
\hline \multicolumn{5}{|l|}{ Heart disease $(\%)$} \\
\hline No & $178(93.2)$ & $132(95.0)$ & $46(88.5)$ & \multirow[t]{2}{*}{0.192} \\
\hline Yes & $13(6.8)$ & $7(5.0)$ & $6(11.5)$ & \\
\hline \multicolumn{5}{|l|}{$\operatorname{COPD}^{\mathrm{a}}(\%)$} \\
\hline No & $169(88.5)$ & $123(88.5)$ & $46(88.5)$ & \multirow[t]{2}{*}{1.000} \\
\hline Yes & $22(11.5)$ & $16(11.5)$ & $6(11.5)$ & \\
\hline \multicolumn{5}{|l|}{ Musculoskeletal disease } \\
\hline No & $58(30.4)$ & $26(18.7)$ & $32(61.5)$ & \multirow[t]{2}{*}{$<0.001$} \\
\hline Yes & $133(69.6)$ & $113(81.3)$ & $20(38.5)$ & \\
\hline \multicolumn{5}{|l|}{ Depression (\%) } \\
\hline No & $163(85.3)$ & $116(83.5)$ & $47(90.4)$ & \multirow[t]{2}{*}{0.260} \\
\hline Yes & $28(14.7)$ & $23(16.5)$ & $5(9.6)$ & \\
\hline \multicolumn{5}{|l|}{ Stroke (\%) } \\
\hline No & $180(94.2)$ & $134(96.4)$ & $46(88.5)$ & \multirow[t]{2}{*}{0.073} \\
\hline Yes & $11(5.8)$ & $5(3.6)$ & $6(11.5)$ & \\
\hline \multicolumn{5}{|l|}{ Dementia } \\
\hline No & 145 (75.9) & $106(76.3)$ & $39(75.0)$ & \multirow[t]{2}{*}{0.851} \\
\hline Yes & $46(24.1)$ & $33(23.7)$ & $13(25.0)$ & \\
\hline \multicolumn{5}{|l|}{ Cancer (\%) } \\
\hline No & $180(94.2)$ & $131(94.2)$ & $49(94.2)$ & \multirow[t]{2}{*}{1.000} \\
\hline Yes & $11(5.8)$ & $8(5.8)$ & $3(5.8)$ & \\
\hline Number of drugs (median [IQR $\left.{ }^{b}\right]$ ) & $3.00[2.00,5.00]$ & $3.00[2.00,5.00]$ & $3.00[2.00,6.00]$ & 0.833 \\
\hline
\end{tabular}

throughout the project. We will specifically compare sociodemographic, clinical and lifestyle variables, as well as their temporal dynamics, which may predict successful ageing and the risk of developing dementia. The ultimate goal of these analyses is to obtain an algorithm that can predict the evolutionary course in healthy and pathological ageing.

\section{RESULTS}

The sociodemographic characteristics of the sample are shown in Table 1. The mean age of the sample was 92.64 years (range: $90-102$ ), $72.8 \%$ females, and $79.1 \%$ widowed. The predominant educational attainment achieved by the sample was primary education $(52.4 \%)$. When asked about occupation $48.2 \%$ of the participants had an occupational status equivalent to unskilled manual labour. Regarding living condition, 23.6\% lived alone, $52.9 \%$ with spouse and $23.6 \%$ with other accompanied. Statistically significant differences were found between males and females, with males being more educated and having more skilled works, while females were older as well as widowed in a greater proportion than males $(\mathrm{p}<0.001)$.

\section{Health status and morbidities}

The sample was diagnosed with or had symptoms of a median of 3 morbidities (IQR: 2-4) and had 3 drugs (IQR: 2-5) on average. Hypertension was the most common vascular risk factor, with $68.1 \%$ of the sample having been diagnosed with it. The rate of previously diagnosed hypercholesterolemia and diabetes mellitus was $13.6 \%$ and $19.4 \%$ respectively. Heart disease was found in $6.8 \%$ of the sample and past stroke was reported by $5.8 \%$. Overall, no significant differences were found between males and females in the diagnosis of cardiovascular disease, although there was a higher tendency among males to suffer from this type of morbidity (Table 2). Musculoskeletal disease (arthrosis / osteoporosis) was however much more prevalent in females than males $(81.3 \%$ vs. $38.5 \%$; p $<0.001)$. Twenty-four percent of the sample was diagnosed with any type of dementia. Finally, the rate of cancer was 
Table 3. Subjective and objective cognitive status of the sample.

\begin{tabular}{|c|c|c|c|c|}
\hline & $\begin{array}{l}\text { TOTAL } \\
(\mathrm{N}=191)\end{array}$ & $\begin{array}{c}\text { FEMALE } \\
(n=139)\end{array}$ & $\begin{array}{l}\text { MALE } \\
(n=52)\end{array}$ & p-value \\
\hline \multicolumn{5}{|l|}{$\operatorname{SCD}^{\mathbf{a}}(\%)$} \\
\hline No & $129(67.5)$ & $95(68.3)$ & $34(65.4)$ & 0.730 \\
\hline Yes & $62(32.5)$ & $44(31.7)$ & $18(34.6)$ & \\
\hline SCD years (median $\left.\left[\mathbf{I Q R} \mathbf{R}^{\mathrm{b}}\right]\right)$ & $3.00[2.00,5.00]$ & $3.00[2.00,5.00]$ & $2.00[1.00,4.75]$ & 0.199 \\
\hline \multicolumn{5}{|l|}{ Concerns $(\%)$} \\
\hline No & $114(59.7)$ & $79(56.8)$ & $35(67.3)$ & 0.246 \\
\hline Yes & $77(40.3)$ & $60(43.2)$ & $17(32.7)$ & \\
\hline \multicolumn{5}{|l|}{ Medical help for SCD (\%) } \\
\hline No & $125(65.4)$ & $89(64.0)$ & $36(69.2)$ & 0.609 \\
\hline Yes & $66(34.6)$ & $50(36.0)$ & $16(30.8)$ & \\
\hline \multicolumn{5}{|l|}{ Daily impact (\%) } \\
\hline No & $120(62.8)$ & $87(62.6)$ & $33(63.5)$ & 1.000 \\
\hline Yes & $71(37.2)$ & $52(37.4)$ & $19(36.5)$ & \\
\hline \multicolumn{5}{|l|}{ Worse than others $(\%)$} \\
\hline No & $148(77.5)$ & $108(77.7)$ & $40(76.9)$ & 1.000 \\
\hline Yes & $43(22.5)$ & $31(22.3)$ & $12(23.1)$ & \\
\hline TICS $^{\mathrm{c}}$ Orientation (median [IQR]) & $9.00[6.00,12.00]$ & $9.00[6.00,11.00]$ & $9.00[5.00,12.00]$ & 0.868 \\
\hline TICS Calculation (median [IQR]) & $0.00[0.00,1.00]$ & $0.00[0.00,1.00]$ & $0.00[0.00,2.00]$ & 0.147 \\
\hline TICS Abstraction (median [IQR]) & $5.00[1.00,8.50]$ & $5.00[1.00,8.00]$ & $5.50[0.75,10.00]$ & 0.313 \\
\hline TICS Immediate Memory (median [IQR]) & $1.00[0.00,3.00]$ & $1.00[0.00,3.00]$ & $2.00[0.00,3.00]$ & 0.237 \\
\hline TICS Delayed Memory (median [IQR]) & $0.00[0.00,1.00]$ & $0.00[0.00,1.00]$ & $0.00[0.00,2.00]$ & 0.423 \\
\hline TICS Working Memory (median [IQR]) & $2.00[0.00,6.00]$ & $2.00[0.00,4.00]$ & $3.00[0.00,7.00]$ & 0.132 \\
\hline TICS Total score (median [IQR]) & $20.00[13.00,26.50]$ & $20.00[13.00,25.00]$ & $21.50[13.00,32.00]$ & 0.343 \\
\hline
\end{tabular}

${ }^{\text {aSCD: }}$ Subjective Cognitive Decline

${ }^{b} \mathrm{IQR}$ : Interquartile range

'TICS; Telephone Interview for Cognitive Status

equal for males and females (5.8\%), being breast, colon, prostate and uterus the most prevalent forms.

\section{Cognitive status}

Approximately one third of the sample reported the presence of cognitive complaints with a median evolution of 3 years (IQR: 2-5). Although $40.3 \%$ of participants showed signs of concern because of the complaints, only $34.6 \%$ reported seeking medical help for this reason. In any case, only $22.5 \%$ acknowledged that they were cognitively worse off than the rest of their age group. No significant differences were found between males and females in SCD (Table 3). Regarding cognitive performance the median of the TICS total score was 20 (IQR: 13-26.5) with males scoring only slightly higher than females ( 21.5 vs. $20.0 ; p=0.343)$. Similarly, no significant differences were found between males and females in any of the TICS subtest, although a slight trend in favour of males was noted in all scores. As expected median cognitive performance in TICS for nondemented was higher and statistically significant than demented ( 23 vs. $9 ; \mathrm{p}<0.001)$. Figure 2 displays the differences between both groups.

\section{Subjective health, quality of life and functionality}

Thirty-five percent of the sample self-reported their general health as being good or very good versus $33.0 \%$

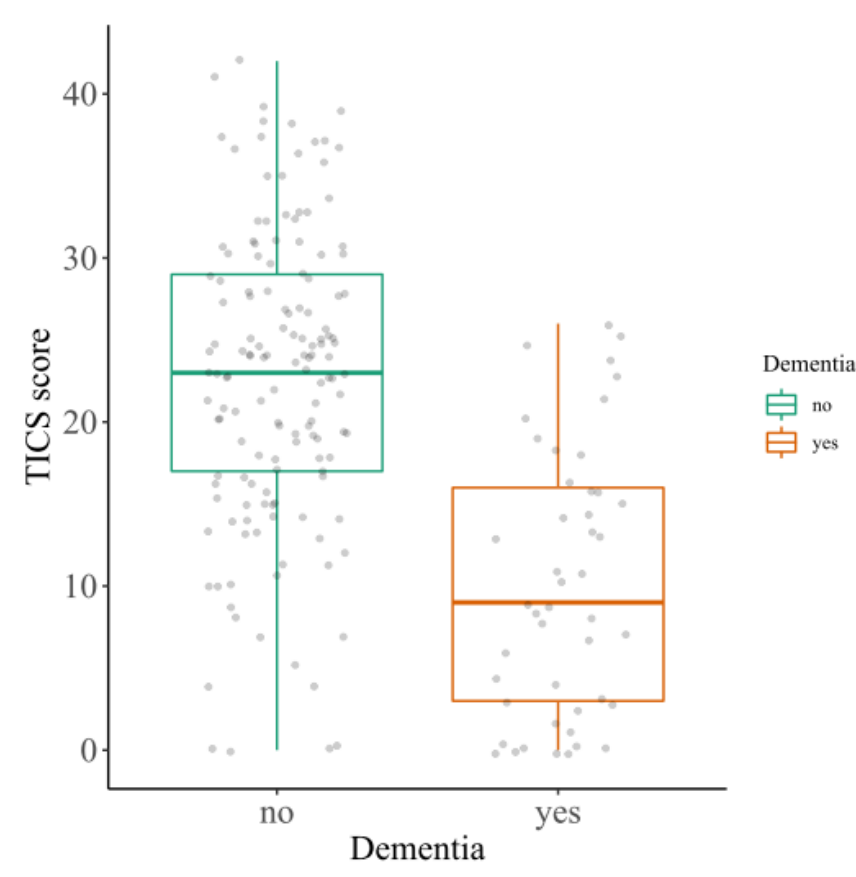

Figure 2. Cognitive performance in TICS by dementia diagnostic.

rating it as fair and $31.9 \%$ as bad or very bad (Table 4). The majority of the participants $(91.6 \%)$ rated their quality of life as good, very good or excellent despite self-reporting $30.4 \%$ of moderate or severe usual pain and $27.2 \%$ poor to very poor sleep quality. With regard to social support, $94.2 \%$ of the sample indicated that they had help from different people if they needed it, although 
Table 4. Self-perceived health, quality of life and functionality of the sample.

\begin{tabular}{|c|c|c|c|c|}
\hline & $\begin{array}{l}\text { TOTAL } \\
(\mathrm{N}=191)\end{array}$ & $\begin{array}{c}\text { FEMALE } \\
(n=139)\end{array}$ & $\begin{array}{c}\text { MALE } \\
(n=52)\end{array}$ & p-value \\
\hline \multicolumn{5}{|l|}{ Self-perceived health (\%) } \\
\hline 1-Very good & $10(5.2)$ & $9(6.5)$ & $1(1.9)$ & 0.480 \\
\hline 2-Good & $57(29.8)$ & $39(28.1)$ & $18(34.6)$ & \\
\hline 3-Neither good nor bad & $63(33.0)$ & $47(33.8)$ & $16(30.8)$ & \\
\hline 4-Bad & $22(11.5)$ & $18(12.9)$ & $4(7.7)$ & \\
\hline 5-Very bad & $39(20.4)$ & $26(18.7)$ & $13(25.0)$ & \\
\hline \multicolumn{5}{|l|}{ Pain $(\%)$} \\
\hline 1-Not at all & $42(22.0)$ & $25(18.0)$ & $17(32.7)$ & 0.273 \\
\hline 2-Very slight & $42(22.0)$ & $32(23.0)$ & $10(19.2)$ & \\
\hline 3-Mild & $49(25.7)$ & $36(25.9)$ & $13(25.0)$ & \\
\hline 4-Moderate & $33(17.3)$ & $27(19.4)$ & $6(11.5)$ & \\
\hline 5-Severe & $25(13.1)$ & $19(13.7)$ & $6(11.5)$ & \\
\hline \multicolumn{5}{|l|}{ Social support (\%) } \\
\hline 0-None & $1(0.5)$ & $0(0.0)$ & $1(1.9)$ & 0.258 \\
\hline 1-Someone & $10(5.2)$ & $8(5.8)$ & $2(3.8)$ & \\
\hline 2-Some people & $31(16.2)$ & $23(16.5)$ & $8(15.4)$ & \\
\hline 3-Many people & $63(33.0)$ & $50(36.0)$ & $13(25.0)$ & \\
\hline 4-Everybody & $86(45.0)$ & $58(41.7)$ & $28(53.8)$ & \\
\hline \multicolumn{5}{|l|}{ Quality of life (\%) } \\
\hline 1-Excellent & $31(16.2)$ & $23(16.5)$ & $8(15.4)$ & 0.885 \\
\hline 2-Very good & $60(31.4)$ & $41(29.5)$ & $19(36.5)$ & \\
\hline 3-Good & $84(44.0)$ & $63(45.3)$ & $21(40.4)$ & \\
\hline 4-Fair & $15(7.9)$ & $11(7.9)$ & $4(7.7)$ & \\
\hline 5-Poor & $1(0.5)$ & $1(0.7)$ & $0(0.0)$ & \\
\hline \multicolumn{5}{|l|}{ Loneliness (\%) } \\
\hline 1-Always & $28(14.7)$ & $21(15.1)$ & $7(13.5)$ & 0.562 \\
\hline 2-Often & $41(21.5)$ & $33(23.7)$ & $8(15.4)$ & \\
\hline 3-Sometimes & $40(20.9)$ & $29(20.9)$ & $11(21.2)$ & \\
\hline 4-Rarely to never & $82(42.9)$ & $56(40.3)$ & $26(50.0)$ & \\
\hline \multicolumn{5}{|l|}{ Disability (\%) } \\
\hline No & $158(82.7)$ & $114(82.0)$ & $44(84.6)$ & 0.830 \\
\hline Yes & $33(17.3)$ & $25(18.0)$ & $8(15.4)$ & \\
\hline \multicolumn{5}{|l|}{ Dependency (\%) } \\
\hline No & $155(81.2)$ & $115(82.7)$ & $40(76.9)$ & 0.407 \\
\hline Yes & $36(18.8)$ & $24(17.3)$ & $12(23.1)$ & \\
\hline \multicolumn{5}{|l|}{ Vision (\%) } \\
\hline Good & $108(56.5)$ & $78(56.1)$ & $30(57.7)$ & 1.000 \\
\hline Moderate & $46(24.1)$ & $34(24.5)$ & $12(23.1)$ & \\
\hline Poor & $3(1.6)$ & $2(1.4)$ & $1(1.9)$ & \\
\hline Very poor & $34(17.8)$ & $25(18.0)$ & $9(17.3)$ & \\
\hline \multicolumn{5}{|l|}{ Hearing (\%) } \\
\hline Good & $108(56.5)$ & $77(55.4)$ & $31(59.6)$ & 0.775 \\
\hline Moderate & $51(26.7)$ & $36(25.9)$ & $15(28.8)$ & \\
\hline Poor & $12(6.3)$ & $10(7.2)$ & $2(3.8)$ & \\
\hline Very poor & $20(10.5)$ & $16(11.5)$ & $4(7.7)$ & \\
\hline \multicolumn{5}{|l|}{ KATZ Index Bath (\%) } \\
\hline Dependent & $78(40.8)$ & $56(40.3)$ & $22(42.3)$ & 0.869 \\
\hline Independent & $113(59.2)$ & $83(59.7)$ & $30(57.7)$ & \\
\hline \multicolumn{5}{|l|}{ KATZ Index Dress (\%) } \\
\hline Dependent & $72(37.7)$ & $54(38.8)$ & $18(34.6)$ & 0.619 \\
\hline Independent & $119(62.3)$ & $85(61.2)$ & $34(65.4)$ & \\
\hline \multicolumn{5}{|l|}{ KATZ Index WC (\%) } \\
\hline Dependent & $63(33.0)$ & $46(33.1)$ & $17(32.7)$ & 1.000 \\
\hline Independent & $128(67.0)$ & $93(66.9)$ & $35(67.3)$ & \\
\hline \multicolumn{5}{|l|}{ KATZ Index Mobility (\%) } \\
\hline Dependent & $65(34.0)$ & $49(35.3)$ & $16(30.8)$ & 0.610 \\
\hline Independent & $126(66.0)$ & $90(64.7)$ & $36(69.2)$ & \\
\hline
\end{tabular}


Table 4. Self-perceived health, quality of life and functionality of the sample.

\begin{tabular}{|c|c|c|c|c|}
\hline & $\begin{array}{c}\text { TOTAL } \\
(\mathrm{N}=191) \\
\end{array}$ & $\begin{array}{c}\text { FEMALE } \\
(n=139)\end{array}$ & $\begin{array}{c}\text { MALE } \\
(n=52)\end{array}$ & p-value \\
\hline \multicolumn{5}{|c|}{ KATZ Index Continence (\%) } \\
\hline Dependent & $75(39.3)$ & $57(41.0)$ & $18(34.6)$ & 0.506 \\
\hline Independent & $116(60.7)$ & $82(59.0)$ & $34(65.4)$ & \\
\hline \multicolumn{5}{|c|}{ KATZ Index Feeding (\%) } \\
\hline Dependent & $46(24.1)$ & $35(25.2)$ & $11(21.2)$ & 0.704 \\
\hline Independent & $145(75.9)$ & $104(74.8)$ & $41(78.8)$ & \\
\hline \multicolumn{5}{|l|}{ Sleep quality (\%) } \\
\hline Good to moderate & $94(49.2)$ & $69(49.6)$ & $25(48.1)$ & 0.532 \\
\hline Intermediate & $45(23.6)$ & $30(21.6)$ & $15(28.8)$ & \\
\hline Poor to very poor & $52(27.2)$ & $40(28.8)$ & $12(23.1)$ & \\
\hline
\end{tabular}

$36.2 \%$ of the participants frequently experienced feelings of loneliness. Rates of disability and dependency in the sample were $17.3 \%$ and $18.8 \%$ respectively, with $80.6 \%$ having moderate or good vision and $83.2 \%$ moderate or good hearing abilities. Katz Index showed that the majority of the participants remain independent for bathing $(59.2 \%)$, continence $(60.7 \%)$, dressing $(62.3 \%)$, mobility $(66.0 \%)$, toileting $(67.0 \%)$, and feeding $(75.9 \%)$. No significant differences by sex were found in all these variables.

\section{Lifestyle characteristics}

While $12.0 \%$ of the participants had smoked at some stage in their lives (males significantly more often than females; $30.8 \%$ vs. $5.0 \%, \mathrm{p}<0.001$ ), only $1.6 \%$ currently smoke. Also, alcohol consumption was low in our sample (4.7\%), with a higher trend among males $(9.6 \%)$.

Regarding diet the daily consumption of fruits, vegetables and extra virgin olive oil stands out, followed by legumes and fish. No significant differences were found in any food group according to sex; only fish consumption was slightly higher among men than among women. On the other hand, walking, watching tv/listening to radio and reading were the most frequent leisure activities among the participants. According to the IQR scores (Table 5), females self-reported a higher level of sedentariness in all the leisure activities. In addition, significant differences were found in favour of men in the activities of meeting friends $(p=0.028)$ and use of ICT $(\mathrm{p}=0.003)$.

\section{DISCUSSION}

MADRID+90 represents one of the few investigations on Spanish oldest-old community-dwelling population. The research programme is divided into two different phases and the main outcomes obtained in Wave 1 have been presented here. Thus, the main aim of this study was to describe health, functional and living condition profiles in 191 individuals over 90 years of age randomly selected from the municipal census of the city of Madrid.
Our results showed that regarding to the sociodemographic profile, females outnumber males by representing $72.8 \%$ of the sample. Females also were found older than males what is an expected result since females live longer than males with a difference in life expectancy at birth around four to six years (Goldin \& Lleras-Muney, 2019). The median morbidity found in our sample was 3, similar to that reported in other population-based studies (Kingston et al., 2018). Hypertension was the most common vascular risk factor, with $68.1 \%$ of the sample having been diagnosed with it. Precisely hypertension is considered as the most common chronic disease of older adults (Interagency Forum on Aging-Related Statistics, 2016) as well as a major contributor to atherosclerosis, which causes inflammation and increases risk for vascular events (Zaheer et al., 2016). There was also a higher tendency among males to suffer from cardiovascular diseases than females; within this category are included chronic ischemic heart disease, heart failure and arrhythmia. On the other hand, rate of cancer for our sample was $5.8 \%$, a very similar rate to that found in a recent populationbased cancer incidence study (DeSantis et al., 2019). After cardiovascular disease, cancer is the second cause of death in older adults. Nevertheless, the risk of receiving a diagnosis of cancer varies throughout the lifespan so that from age 85 the risk begins to decrease, as does the death rate associated with cancer (White et al., 2014). Thus, after age 90 cancer is an uncommon cause of disease or death (Pavlidis et al., 2012).

Disability rates are usually high among oldest-old population. Previous studies have reported that the prevalence of disability increases exponentially in older adults, especially at the age of 85 (Guay et al., 2014). In our study we found that around $60 \%$ of the sample is dependent for at least one daily living activity as proposed in the Katz Index. This finding is consistent with previous studies that have reported 21.5-66\% nonagenarians with difficulties in one or more daily living activities (Berlau et al., 2009; Guay et al., 2014). We also found that among self-care activities bathing has the highest prevalence of disability among 
nonagenarians, as previously reported (Gill et al., 2006; Naik et al., 2004). Regarding vision, visual acuity tends to decrease with age producing different types of impairments. In our sample $17 \%$ of individuals showed signs of very poor vision, a slightly better figure than that provided in other studies (Evans et al., 2002). On the other hand, hearing loss also increases with ageing. Our results showed a $10.5 \%$ of prevalence of very poor hearing what is in line with other studies that estimate a
6-7\% of severe hearing loss (Goman \& Lin, 2016; Göthberg et al., 2020). Both visual impairment and especially hearing loss are two main disabilities that are associated with higher risks for social isolation, depression, dementia, and dependency. Hearing aids are underused in this population despite their potential benefits. To improve use, hearing aids should be thought of as a lifestyle modification for fostering longevity (Wattamwar et al., 2017).

Table 5. Lifestyle characteristics of the sample.

\begin{tabular}{|c|c|c|c|c|}
\hline & $\begin{array}{c}\text { TOTAL } \\
(\mathrm{N}=191)\end{array}$ & $\begin{array}{c}\text { FEMALE } \\
(n=139)\end{array}$ & $\begin{array}{c}\text { MALE } \\
(n=52)\end{array}$ & p-value \\
\hline \multicolumn{5}{|l|}{ Smoking (\%) } \\
\hline Currently & $3(1.6)$ & $2(1.4)$ & $1(1.9)$ & $<0.001$ \\
\hline In the past & $23(12.0)$ & $7(5.0)$ & $16(30.8)$ & \\
\hline Never & $165(86.4)$ & $130(93.5)$ & $35(67.3)$ & \\
\hline \multicolumn{5}{|l|}{ Alcohol (\%) } \\
\hline Currently & $9(4.7)$ & $4(2.9)$ & $5(9.6)$ & 0.064 \\
\hline Never & $182(95.3)$ & $135(97.1)$ & $47(90.4)$ & \\
\hline Vegetables (median $\left[I_{Q} R^{\mathrm{a}}\right]$ ) & $4.00[3.00,4.00]$ & $4.00[3.00,4.00]$ & $4.00[3.00,4.00]$ & 0.807 \\
\hline Fruit (median [IQR]) & $4.00[4.00,4.00]$ & $4.00[4.00,4.00]$ & $4.00[4.00,4.00]$ & 0.686 \\
\hline Extra virgin olive oil (median [IQR]) & $4.00[3.00,4.00]$ & $4.00[3.00,4.00]$ & $4.00[3.00,4.00]$ & 0.865 \\
\hline Legumes (median [IQR]) & $2.00[2.00,3.00]$ & $2.00[2.00,3.00]$ & $2.00[2.00,3.00]$ & 0.170 \\
\hline Fish (median [IQR]) & $2.00[1.00,2.00]$ & $2.00[1.00,2.00]$ & $2.00[2.00,3.00]$ & 0.097 \\
\hline Nuts (median [IQR]) & $0.00[0.00,2.00]$ & $0.00[0.00,1.00]$ & $0.00[0.00,2.00]$ & 0.385 \\
\hline Coffee (median [IQR]) & $1.00[0.00,4.00]$ & $1.00[0.00,4.00]$ & $2.00[0.00,4.00]$ & 0.392 \\
\hline Walking (median [IQR]) & $3.00[0.00,4.00]$ & $2.00[0.00,4.00]$ & $3.50[0.00,4.00]$ & 0.470 \\
\hline Other physical activity (median [IQR]) & $0.00[0.00,0.00]$ & $0.00[0.00,0.00]$ & $0.00[0.00,0.00]$ & 0.062 \\
\hline Artistic (median [IQR]) & $0.00[0.00,0.00]$ & $0.00[0.00,0.00]$ & $0.00[0.00,0.00]$ & 0.643 \\
\hline Meet friends (median [IQR]) & $0.00[0.00,0.00]$ & $0.00[0.00,0.00]$ & $0.00[0.00,2.00]$ & 0.028 \\
\hline Pastime (median [IQR]) & $0.00[0.00,0.00]$ & $0.00[0.00,0.00]$ & $0.00[0.00,2.00]$ & 0.192 \\
\hline Courses (median [IQR]) & $0.00[0.00,0.00]$ & $0.00[0.00,0.00]$ & $0.00[0.00,0.00]$ & 0.196 \\
\hline Cinema (median [IQR]) & $0.00[0.00,0.00]$ & $0.00[0.00,0.00]$ & $0.00[0.00,0.00]$ & 0.899 \\
\hline Music (median [IQR]) & $0.00[0.00,1.00]$ & $0.00[0.00,0.00]$ & $0.00[0.00,1.25]$ & 0.261 \\
\hline TV / Radio (median [IQR]) & $4.00[1.00,4.00]$ & $4.00[1.00,4.00]$ & $4.00[3.25,4.00]$ & 0.681 \\
\hline Reading (median [IQR]) & $1.00[0.00,4.00]$ & $0.00[0.00,4.00]$ & $1.00[0.00,4.00]$ & 0.272 \\
\hline ICT $^{\mathbf{b}}($ median [IQR] $)$ & $0.00[0.00,1.00]$ & $0.00[0.00,0.00]$ & $0.00[0.00,3.25]$ & 0.003 \\
\hline
\end{tabular}

The results of MADRID+90 Wave 1 showed that $24.1 \%$ of individuals had been diagnosed as demented by their physicians. However, distinguishing between normal and pathological ageing in the oldest-old is particularly difficult. The lack of adapted and validated cognitive assessment tools for this population group, together with the lack of operational definitions of cognitive impairment, make diagnosis difficult in people over 90 years of age (Giulioli \& Amieva, 2016). Compared to younger older adults, individuals over 90 have greater variability that increases the difficulty for their clinical, social and cognitive study. In addition, as a collateral effect to their exceptional longevity, there is a high percentage of people over 90 with sensory (visual or auditory) and/or psychomotor disabilities, which is an impediment to carry out any standard neurocognitive examination (Gussekloo et al., 2005). As a result there is an evident lack of consensus about the criteria for diagnosing dementia from the age of 90 onwards (Slavin et al., 2013). This lack of consensus leads to notable discrepancies on epidemiological data. For example, some studies have suggested a decrease in the prevalence of dementia in very old individuals with respect to earlier ages (Fichter et al., 1995), obtaining dementia rates in people over 90 years of $22.1 \%$ for men and $30.8 \%$ for women (Lobo et al., 2000), which stagnate around 40\% at age 95 (Ritchie \& Kildea, 1995), or even show a deceleration in prevalence-incidence/age (Gao et al., 1998). But on the other hand, other studies indicate that both the incidence and prevalence of dementia continue to increase in nonagenarians and centenarians (Corrada et al., 2008), and that it could even do so with the same rate as in the less elderly age groups (Corrada et al., 2010). Specifically, in centenarians, dementia prevalence rates are even more contradictory, with percentages ranging from $25-100 \%$ depending on the studies 
(Blansjaar et al., 2000). All these discrepancies could be explained, at least in part, due to the lack of systematic research in the oldest-old and the extreme complexity of precisely defining the diagnostic criteria.

Effective strategies are needed to maintain the best possible health and well-being later in life. The key role that lifestyle plays in the paradigm shift of longevity and ageing cannot be overlooked. Variables such as diet, physical activity, economic status, education, social relationships, stress or socio-cultural context have been repeatedly researched and are pieces of a puzzle that could help increase life expectancy and quality of life. Our results show that although $12 \%$ of the participants had smoked at some stage in their lives, especially males, only $1.6 \%$ currently smoke. Moreover, significant alcohol consumption was very low in our sample (4.7\%) with a higher trend again among males. Regarding diet the daily consumption of fruits, vegetables and extra virgin olive oil stands out, followed by legumes and fish. Those foods are good indicators of compliance with a Mediterranean diet, which has been repeatedly associated with longevity (Livingston et al., 2017). On the other hand, walking, watching tv/listening to radio and reading were the most frequent leisure activities, with females self-reported a higher level of sedentariness in all the leisure activities that perhaps could be related with their older age. Specifically, the inherent benefits of maintaining a healthy lifestyle can be classified into groups according to their susceptibility to being easily modifiable or not. This classification will be instrumental in establishing individualized longevity strategies: (i) variables related to sociodemographic factors (not easily modifiable): income level, educational attainment, place of residence, marital status, employment, environmental pollution; and (ii) variables related to lifestyle (apparently more easily modifiable): nutrition, overweight, physical activity, intellectual activity, hours and quality of sleep, social network, life satisfaction, stress, and leisure activities. All the above external and environmental factors have the capacity to regulate the expression of certain genes and, consequently, to activate or inhibit their expression.

In summary, while the expected strong demographic change poses major challenges to societies in economic, health and ethical terms, this unprecedented situation presents itself as an opportunity to understand the determinants of healthy ageing and longevity. Nonagenarians and centenarians can no longer be seen as a statistical anomaly, but as a growing segment of the population of invaluable importance in identifying key factors related to successful ageing. In the next 20 years societies will be forced to face this challenge in order to minimise its social, sanitary and economic consequences. The study of the biopsychosocial and clinical profile of the oldest-old will help in making political decisions regarding public health. In addition, the study of very old individuals who have successfully aged will also help to decipher the combination of lifestyle factors, therefore modifiable, that allow to prevent age-related diseases, especially dementia and, mainly, AD. Ultimately, healthy aging must allow the maintenance of life as long as possible, full, active and without suffering caused by diseases that limit physical or cognitive capacity. And these are the objectives that MADRID+90 aspires to.

\section{Acknowledgments}

We wish to thank the research participants for their kindly collaboration.

\section{Author contributions}

All authors are responsible for the conceptualization, reviewing the literature, and critically editing the manuscript. All authors approve the submitted version of the manuscript and are accountable for the accuracy and integrity of the work.

\section{Conflict of interest disclosures}

The authors report no conflicts of interest relevant to the manuscript.

\section{Funding/support}

This study was supported and funded by the Fundación General de la Universidad de Salamanca (FGUSAL) through the Centro Internacional sobre el Envejecimiento (CENIE) under the Grant 0348_CIE_6_E by Fondos FEDER EU.

\section{REFERENCES}

Ashendorf, L., Vanderslice-Barr, J. L., \& McCaffrey, R. J. (2009). Motor Tests and Cognition in Healthy Older Adults. Applied Neuropsychology, 16(3), 171-176. https://doi.org/10.1080/09084280903098562

Berlau, D. J., Corrada, M. M., \& Kawas, C. (2009). The prevalence of disability in the oldest-old is high and continues to increase with age: Findings from the $90+$ Study. International Journal of Geriatric Psychiatry, 24(11), 1217-1225. https://doi.org/10.1002/gps.2248

Berrington de Gonzalez, A., Hartge, P., Cerhan, J. R., Flint, A. J., Hannan, L., MacInnis, R. J., Moore, S. C., Tobias, G. S., Anton-Culver, H., Freeman, L. B., Beeson, W. L., Clipp, S. L., English, D. R., Folsom, A. R., Freedman, D. M., Giles, G., Hakansson, N., Henderson, K. D., HoffmanBolton, J., ... Thun, M. J. (2010). Body-Mass Index and Mortality among 1.46 Million White Adults. New England Journal of Medicine, 363(23), 22112219. https://doi.org/10.1056/NEJMoa 1000367

Blansjaar, B. A., Thomassen, R., \& Van Schaick, H. W. (2000). Prevalence of dementia in centenarians. International Journal of Geriatric Psychiatry, 15(3), 
http://www.ncbi.nlm.nih.gov/pubmed/10713579

Boyle, P. A., Buchman, A. S., Barnes, L. L., \& Bennett, D. A. (2010). Effect of a Purpose in Life on Risk of Incident Alzheimer Disease and Mild Cognitive Impairment in Community-Dwelling Older Persons. Archives of General Psychiatry, 67(3), 304.

https://doi.org/10.1001/archgenpsychiatry.2009.20 8

Buschke, H. (1984). Cued recall in amnesia. Journal of Clinical Neuropsychology, 6(4), 433-440. https://doi.org/10.1080/01688638408401233

Cacho, J., García-García, R., Arcaya, J., Vicente, J. L., \& Lantada, N. (1999). [A proposal for application and scoring of the Clock Drawing Test in Alzheimer's disease]. Revista de Neurología, 28(7), 648-655.

Corrada, M. M., Brookmeyer, R., Berlau, D., PaganiniHill, A., \& Kawas, C. H. (2008). Prevalence of dementia after age 90: Results from the 90+ study. Neurology.

https://doi.org/10.1212/01.wnl.0000310773.65918 .cd

Corrada, M. M., Brookmeyer, R., Paganini-Hill, A., Berlau, D., \& Kawas, C. H. (2010). Dementia incidence continues to increase with age in the oldest old: The 90+ study. Annals of Neurology, 67(1), 114-121. https://doi.org/10.1002/ana.21915

DeSantis, C. E., Miller, K. D., Dale, W., Mohile, S. G., Cohen, H. J., Leach, C. R., Goding Sauer, A., Jemal, A., \& Siegel, R. L. (2019). Cancer statistics for adults aged 85 years and older, 2019. CA: A Cancer Journal for Clinicians, 69(6), 452-467. https://doi.org/10.3322/caac.21577

Dubois, B., Slachevsky, A., Litvan, I., \& Pillon, B. (2000). The FAB: A frontal assessment battery at bedside. Neurology, 55(11), 1621-1626. https://doi.org/10.1212/WNL.55.11.1621

Evans, J. R., Fletcher, A. E., Wormald, R. P. L., Ng, E. S. W., Stirling, S., Smeeth, L., Breeze, E., Bulpitt, C. J., Nunes, M., Jones, D., \& Tulloch, A. (2002). Prevalence of visual impairment in people aged 75 years and older in Britain: Results from the MRC trial of assessment and management of older people in the community. British Journal of Ophthalmology, $\quad$ 86(7), $\quad$ 795-800. https://doi.org/10.1136/bjo.86.7.795

Fernández-Blázquez, M A, Ávila-Villanueva, M., López-Pina, J. A., Zea-Sevilla, M. A., \& FradesPayo, B. (2015). Psychometric properties of a new short version of the State-Trait Anxiety Inventory (STAI) for the assessment of anxiety in the elderly. Neurologia (Barcelona, Spain), 30(6), 352-358. https://doi.org/10.1016/j.nrl.2013.12.015

Fernández-Blázquez, Miguel A., Ávila-Villanueva, M., \& Medina, M. (2018). The dimensional structure of subjective cognitive decline. In Neuromethods (Vol. 137, pp. 45-62). Humana Press Inc. https://doi.org/10.1007/978-1-4939-7674-4 3

Fernández-Blázquez, Miguel A, Ruiz-Sánchez de León, J. M., López-Pina, J. A., Llanero-Luque, M., Montenegro-Peña, M., \& Montejo-Carrasco, P. (2012). [A new shortened version of the Boston Naming Test for those aged over 65: an approach from item response theory]. Revista de Neurologia, 55(7), 399-407.

Fichter, M. M., Meller, I., Schröppel, H., \& Steinkirchner, R. (1995). Dementia and cognitive impairment in the oldest old in the community. Prevalence and comorbidity. The British Journal of Psychiatry: The Journal of Mental Science, 166(5), 621-629.

http://www.ncbi.nlm.nih.gov/pubmed/7620747

Folstein, M. F., Folstein, S. E., \& McHugh, P. R. (1975). "Mini-mental state": A practical method for grading the cognitive state of patients for the clinician. Journal of Psychiatric Research, 12(3), 189-198. 3956(75)90026-6

Gao, S., Hendrie, H. C., Hall, K. S., \& Hui, S. (1998). The relationships between age, sex, and the incidence of dementia and Alzheimer disease: a meta-analysis. Archives of General Psychiatry, 55(9), 809-815. http://www.ncbi.nlm.nih.gov/pubmed/9736007

Gill, T. M., Guo, Z., \& Allore, H. G. (2006). The epidemiology of bathing disability in older persons. Journal of the American Geriatrics Society, 54(10), 1524-1530. https://doi.org/10.1111/j.15325415.2006.00890.x

Giulioli, C., \& Amieva, H. (2016). Epidemiology of Cognitive Aging in the Oldest Old. Revista de Investigación Clínica, 68, 33-39. www.permanyer.com

Goldin, C., \& Lleras-Muney, A. (2019). XX > XY?: The changing female advantage in life expectancy. Journal of Health Economics, 67. https://doi.org/10.1016/j.jhealeco.2019.102224

Goman, A. M., \& Lin, F. R. (2016). Prevalence of hearing loss by severity in the United States. American Journal of Public Health, 106(10), 1820 1822. https://doi.org/10.2105/AJPH.2016.303299

Göthberg, H., Rosenhall, U., Tengstrand, T., Rydén, L., Wetterberg, H., Skoog, I., \& Sadeghi, A. (2020). Prevalence of hearing loss and need for aural rehabilitation in 85-year-olds: a birth cohort comparison, almost three decades apart. International Journal of Audiology, 1-10. https://doi.org/10.1080/14992027.2020.1734878

Guay, M., Dubois, M. F., Corrada, M., Lapointe-Garant, M. P., \& Kawas, C. (2014). Exponential Increases in the Prevalence of Disability in the Oldest Old: A Canadian National Survey. Gerontology, 60(5), 395-401. https://doi.org/10.1159/000358059

Gussekloo, J., de Craen, A. J. M., Oduber, C., van Boxtel, 
M. P. J., \& Westendorp, R. G. J. (2005). Sensory Impairment and Cognitive Functioning in OldestOld Subjects: The Leiden 85+ Study. American Journal of Geriatric Psychiatry, 13(9), 781-786. https://doi.org/10.1176/appi.ajgp.13.9.781

Hadley, E. C., Kuchel, G. A., Newman, A. B., Allore, H. G., Bartley, J. M., Bergeman, C. S., Blinov, M. L., Colon-Emeric, C. S., Dabhar, F. S., Dugan, L. L., Dutta, C., Eldadah, B. A., Ferrucci, L., Kirkland, J. L., Kritchevsky, S. B., Lipsitz, L. A., Nadkarni, N. K., Reed, M. J., Schmader, K. E., ... Yung, R. (2017). Report: NIA Workshop on Measures of Physiologic Resiliencies in Human Aging. The Journals of Gerontology: Series A, 72(7), 980-990. https://doi.org/10.1093/gerona/glx015

Holstege, H., Beker, N., Dijkstra, T., Pieterse, K., Wemmenhove, E., Schouten, K., Thiessens, L., Horsten, D., Rechtuijt, S., Sikkes, S., van Poppel, F. W. A., Meijers-Heijboer, H., Hulsman, M., \& Scheltens, P. (2018). The 100-plus Study of cognitively healthy centenarians: rationale, design and cohort description. European Journal of Epidemiology, 33(12), 1229-1249. https://doi.org/10.1007/s10654-018-0451-3

Holt-Lunstad, J., Smith, T. B., \& Layton, J. B. (2010). Social Relationships and Mortality Risk: A Metaanalytic Review. PLoS Medicine, 7(7), e1000316. https://doi.org/10.1371/journal.pmed.1000316

Interagency Forum on Aging-Related Statistics, F. (2016). Older Americans 2016: Key Indicators of Well-Being. http://www.dol.gov/ebsa

Kingston, A., Robinson, L., Booth, H., Knapp, M., Jagger, C., Adelaja, B., Avendano, M., Bamford, S. M., Banerjee, S., Berwald, S., Bowling, A., Burgon, C., Bustard, E., Comas-Herrera, A., Dangoor, M., Dixon, J., Farina, N., Greengross, S., Grundy, E., ... Wittenberg, R. (2018). Projections of multi-morbidity in the older population in England to 2035: Estimates from the Population Ageing and Care Simulation (PACSim) model. Age and Ageing. https://doi.org/10.1093/ageing/afx201

Landi, F., Calvani, R., Picca, A., Tosato, M., D’Angelo, E., Martone, A. M., Serafini, E., Ortolani, E., Savera, G., Salini, S., Acampora, N., Bernabei, R., \& Marzetti, E. (2018). Relationship between cardiovascular health metrics and physical performance in community-living people: Results from the Longevity check-up (Lookup) 7+ project. Scientific Reports, 8(1), 1-8. https://doi.org/10.1038/s41598-018-34746-4

Lawton, M. P., \& Brody, E. M. (1969). Assessment of older people: Self-maintaining and instrumental activities of daily living. Gerontologist, 9(3), 179186. https://doi.org/10.1093/geront/9.3_Part_1.179

Livingston, G., Sommerlad, A., Orgeta, V., Costafreda, S. G., Huntley, J., Ames, D., Ballard, C., Banerjee, S., Burns, A., Cohen-Mansfield, J., Cooper, C.,
Fox, N., Gitlin, L. N., Howard, R., Kales, H. C., Larson, E. B., Ritchie, K., Rockwood, K., Sampson, E. L., ... Mukadam, N. (2017). Dementia prevention, intervention, and care. In The Lancet (Vol. 390, Issue 10113, pp. 2673-2734). Lancet Publishing Group. https://doi.org/10.1016/S01406736(17)31363-6

Lobo, A., Launer, L. J., Fratiglioni, L., Andersen, K., Di Carlo, A., Breteler, M. M., Copeland, J. R., Dartigues, J. F., Jagger, C., Martinez-Lage, J., Soininen, H., \& Hofman, A. (2000). Prevalence of dementia and major subtypes in Europe: A collaborative study of population-based cohorts. Neurologic Diseases in the Elderly Research Group. Neurology, 54(11 Suppl 5), S4-9. http://www.ncbi.nlm.nih.gov/pubmed/10854354

Morris, J. C. (1993). The clinical dementia rating (CDR): Current version and scoring rules. Neurology, 43(11), 2412-2414. https://doi.org/10.1212/wnl.43.11.2412-a

Naghshi, S., Sadeghi, O., Willett, W. C., \& Esmaillzadeh, A. (2020). Dietary intake of total, animal, and plant proteins and risk of all cause, cardiovascular, and cancer mortality: Systematic review and dose-response meta-analysis of prospective cohort studies. The BMJ, 370, 2412. https://doi.org/10.1136/bmj.m2412

Naik, A. D., Concato, J., \& Gill, T. M. (2004). Bathing disability in community-living older persons: Common, consequential, and complex. Journal of the American Geriatrics Society, 52(11), 1805$1810 . \quad$ https://doi.org/10.1111/j.15325415.2004.52513.x

Nations, U. (2014). Probabilistic Population Projections based on the World Population Prospects: The 2012 Revision. In Population Division Department of Economic and Social Affairs. http://esa.un.org/unpd/ppp/

Olazarán, J., Valentí, M., Frades, B., Zea-Sevilla, M. A., Ávila-Villanueva, M., Fernández-Blázquez, M. Á., Calero, M., Dobato, J. L., Hernández-Tamames, J. A., León-Salas, B., Agüera-Ortiz, L., LópezÁlvarez, J., Larrañaga, P., Bielza, C., ÁlvarezLinera, J., \& Martínez-Martín, P. (2015). The Vallecas Project A Cohort to Identify Early Markers and Mechanisms of Alzheimer's Disease. Frontiers in Aging Neuroscience, 7, 181. https://doi.org/10.3389/fnagi.2015.00181

Pavlidis, N., Stanta, G., \& Audisio, R. A. (2012). Cancer prevalence and mortality in centenarians: A systematic review. In Critical Reviews in Oncology/Hematology (Vol. 83, Issue 1, pp. 145152). Crit Rev Oncol Hematol. https://doi.org/10.1016/j.critrevonc.2011.09.007

Peña-Casanova, J. (2005). Normalidad, semiología y patología neuropsicológicas. Programa Integrado de Exploración Neuropsicológica. Test Barcelona 
Revisado. (Barcelona:).

Peña-Casanova, J., Quiñones-Ubeda, S., GramuntFombuena, N., Quintana-Aparicio, M., Aguilar, M., Badenes, D., Cerulla, N., Molinuevo, J. L., Ruiz, E., Robles, A., Barquero, M. S., Antúnez, C., Martínez-Parra, C., Frank-García, A., Fernández, M., Alfonso, V., Sol, J. M., \& Blesa, R. (2009). Spanish Multicenter Normative Studies (NEURONORMA Project): norms for verbal fluency tests. Archives of Clinical Neuropsychology, 24(4), 395-411. https://doi.org/10.1093/arclin/acp042

Perls, T. T., Wilmoth, J., Levenson, R., Drinkwater, M., Cohen, M., Bogan, H., Joyce, E., Brewster, S., Kunkel, L., \& Puca, A. (2002). Life-long sustained mortality advantage of siblings of centenarians. Proceedings of the National Academy of Sciences, 99(12), https://doi.org/10.1073/pnas.122587599

Pignolo, R. J. (2019). Exceptional Human Longevity. Mayo Clinic Proceedings, 94(1), 110-124. https://doi.org/10.1016/j.mayocp.2018.10.005

Podsiadlo, D., \& Richardson, S. (1991). The Timed "Up \&amp; Go": A Test of Basic Functional Mobility for Frail Elderly Persons. Journal of the American Geriatrics Society, 39(2), 142-148. https://doi.org/10.1111/j.15325415.1991.tb01616.x

Revelas, M., Thalamuthu, A., Oldmeadow, C., Evans, T. J., Armstrong, N. J., Kwok, J. B., Brodaty, H., Schofield, P. R., Scott, R. J., Sachdev, P. S., Attia, J. R., \& Mather, K. A. (2018). Review and metaanalysis of genetic polymorphisms associated with exceptional human longevity. In Mechanisms of Ageing and Development (Vol. 175, pp. 24-34). Elsevier Ireland Ltd. https://doi.org/10.1016/j.mad.2018.06.002

Ritchie, K., \& Kildea, D. (1995). Is senile dementia \&quot;age-related\&quot; or \&quot;ageingrelated\&quot;?--evidence from meta-analysis of dementia prevalence in the oldest old. Lancet (London, England), 346(8980), 931-934. http://www.ncbi.nlm.nih.gov/pubmed/7564727

Rivoirard, R., Chargari, C., Tronec, J. C., Falk, A. T., Guy, J. B., Eddekkaoui, H., Lahmar, R., Pacaut, C., Mery, B., Assouline, A., Auberdiac, P., Moriceau, G., Gonthier, R., Guillota, A., Merrouche, Y., \& Magne, N. (2014). General management of nonagenarian patients: A review of the literature. In Swiss Medical Weekly. https://doi.org/10.4414/smw.2014.14059

Slavin, M. J., Brodaty, H., \& Sachdev, P. S. (2013). Challenges of Diagnosing Dementia in the Oldest Old Population. The Journals of Gerontology Series A: Biological Sciences and Medical Sciences, 68(9), 1103-1111. https://doi.org/10.1093/gerona/glt051
Spielberger, C., Gorsuch, R., \& Leshene, R. (1970). Manual for the State-Trait Anxiety Inventory. Consulting Psychologists Press.

Warrington, E. K., \& James, M. (1991). The Visual Object and Space Perception Battery. In Thames Valley Test Company. https://doi.org/Thesis_references-Converted \#318

Wattamwar, K., Jason Qian, Z., Otter, J., Leskowitz, M. J., Caruana, F. F., Siedlecki, B., Spitzer, J. B., \& Lalwani, A. K. (2017). Increases in the rate of agerelated hearing loss in the older old. JAMA Otolaryngology - Head and Neck Surgery, 143(1), 41-45. https://doi.org/10.1001/jamaoto.2016.2661

Wechsler, D. (1997). Wechsler Adult Intelligence ScaleIII. The Psychological Corporation.

White, M. C., Holman, D. M., Boehm, J. E., Peipins, L. A., Grossman, M., \& Jane Henley, S. (2014). Age and cancer risk: A potentially modifiable relationship. American Journal of Preventive Medicine, $46(3 \quad$ SUPPL. 1$), \quad$ S7. https://doi.org/10.1016/j.amepre.2013.10.029

Yesavage, J. A., Brink, T. L., Rose, T. L., Lum, O., Huang, V., Adey, M., \& Leirer, V. O. (1982). Development and validation of a geriatric depression screening scale: a preliminary report. Journal of Psychiatric Research, 17(1), 37-49. https://doi.org/10.1016/0022-3956(82)90033-4

Zaheer, M., Chrysostomou, P., \& Papademetriou, V. (2016). Hypertension and atherosclerosis: Pathophysiology, mechanisms and benefits of BP control. In Hypertension and Cardiovascular Disease (pp. 201-216). Springer International Publishing. https://doi.org/10.1007/978-3-31939599-9_14 